\title{
The Belt and Road Initiative: Research on Creative Mode of Talent Training in Cultural Industry
}

\author{
Pan Yingli \\ Ideological and Political Department Xi'an Peihua University \\ $\mathrm{Xi}$ 'an, shaanxi province \\ e-mail:79255432@qq.com
}

\begin{abstract}
Along with the economic globalization and internationalization of education, international education exchanges have become increasingly frequent, in the background of "The Belt and Road" under the national strategy, the cultural industry market and the market need to adapt to the needs of the cultural industry professionals. At present, the personnel training mode of cultural industry in our country is still in the stage of exploration. There are some problems such as unclear subject orientation, unreasonable professional setting, heavy theory and light practice. Therefore, under the new situation, it is of important theoretical and practical significance to explore a scientific and rational innovation model of talent training in the cultural industry.
\end{abstract}

Keywords-The Belt and Road; Initiative Culture; Industry Personnel Training

\section{INTRODUCTION}

"Belt and Road Initiative" strategy is the construction of "Silk Road Economic Belt" and "twenty-first Century Maritime Silk Road strategy, it is the inheritance and development of the ancient Silk Road, the Silk Road on the sea, is an important strategic planning of the current government. "The Belt and Road" strategy not only rely on hard power, but also on soft power. Hard power includes economic strength, political power, diplomatic strength and military strength. The most important factor in soft power is talent. Because talent is the basic condition of economic development is essential, not adapt to the new international talent environment, it is difficult to open the door of the market of other countries, it is difficult to grasp the right words in "The Belt and Road" strategy.

\section{THE CONCEPT OF CULTURAL INDUSTRY AND THE EVOLUTION OF ITS CONNOTATION}

Cultural and creative industries, is produced under the background of economic globalization to creativity as the core of the emerging industry, emphasize a kind of culture or cultural factors rely on personal (team) through technology, creative and industrialization development, marketing of intellectual property industry. Cultural and creative industries including radio and television, animation, video, media, visual arts, performing arts, crafts and design, sculpture, environmental art, advertisement decoration, clothing design, software and computer services and other aspects of the creative group.

There are few of the vocabulary of cultural and creative industries "state in the world, more is the" creative industries "or" creative economy ", also known as" cultural industry "(such as the UK)," the content industry "(such as the Australia) and" copyright industries "(such as the United States with other references) but, on the connotation and extension of countries (regions) that are similar but. This objective fact shows that there is no widely accepted and accepted definition about the connotation of cultural and creative industries.

UNESCO also defines the cultural and creative industries, which rely on the creativity of human wisdom and skills and talents, with the help of the cultural resources in the creation and promotion of high-tech, through the 
development and use of intellectual property rights, to produce high value-added products, has created wealth and employment potential of the industry is the cultural and creative industries it contains, cultural products and cultural services and intelligent property rights three items.

Generally speaking, the debate about the concept of cultural and creative industries is mainly reflected in the scope of the definition of industry and departments, which is divided into two types. The first is a relatively broad definition: such as Hawkins, Hongkong and Shanghai are typical, as long as contains "creativity" and "intellectual property" activities can be called creative industries, and departments are defined more broadly, involving all sectors of the national economy. The second is a narrower definition, the definition of Caves and Taiwan as the representative, its connotation is relatively concentrated in the arts and culture, emphasizing the contribution of culture to economy, to a certain extent can be equated to the connotation of "cultural industry". In summary, all countries (regions) of scholars to understand the meaning of creative industry are relatively close, emphasize the contribution ability of creativity on the economy, focusing on the definition of the whole industry chain, mainly composed of the three elements of industry, industry and industry source path of social effect, the emphasis on the "creative" as the core source. At the same time, "creativity" as a basic industry is a common understanding among scholars in different countries and regions, although there are different views on the definition of creative industries. The core periphery industry composed of industry and industry categories, core production industry is mainly concentrated in the upstream, while the peripheral industry is the supporting industry, mainly concentrated in the exchange and distribution in the downstream, covering education and training, leisure and tourism etc.

\section{THE DEVELOPMENT OF THE CULTURAL INDUSTRY}

NEEDS THE TALENTS OF THE CULTURAL INDUSTRY

Under the condition of prosperity and development of the cultural industry, the demand for talents in the cultural industry has become a pressing problem. According to the classification of the cultural industry, our country needs relevant talents in the core layer of cultural industry, such as film and television, radio, books, animation and so on. In March 2005, the Beijing municipal government issued the "Beijing management regulations" to attract top talent award, cultural industry management personnel outstanding talents will be included in the category, and multinational executives, software executives and celebrities together to enjoy preferential treatment in Beijing City, the highest reward amount can be as high as 300 thousand yuan.

According to the survey, as a new engine of economic development, culture industry has accelerated its development and has become a broad consensus among party committees and governments at all levels. All provinces and cities attach great importance to the development of cultural and creative industries, forming a working force and a sound mechanism conducive to the development of cultural and creative industries, and have done a great deal of work in training and introducing talents in the field of literary and creative industries. But with the economy to accelerate the transformation and upgrading, the cultural and creative industries talent bottleneck is becoming more and more serious, such as high-end, lack of talents, the shortage of creative talents, the shortage of education, training and the demand of the market, training system is not perfect. In view of these short boards, while continuing to increase the intensity of talent introduction, we should pay more attention to personnel training.

At present, there are three prominent problems in the training of talents in the cultural industry. First, the training target is not clear enough, the professional setting is not reasonable, and the talent training of cultural industry and market demand are out of line. Two, there is the tendency of emphasizing theory, neglecting practice, valuing knowledge accumulation and neglecting hands-on operation. Students learn more about theoretical knowledge of culture industry, but lack innovation ability in practice. Three is to the cultural industry talent "creative" training is not enough, creative talent is less. At present, the training of creative talents in the cultural industry in our country needs to be improved urgently. Therefore, we must take effective 
measures to deal with the outstanding problems of these three aspects in order to train talents in China's cultural industries.

\section{EXPLORATION OF CREATIVE MODE OF TALENT TRAINING IN CULTURAL INDUSTRY}

1) Making scientific planning of talent training in Chinese cultural industry. The construction of a reasonable structure, have both ability and political integrity and innovation, large-scale cultural industry personnel, and to adapt to the cultural industry talent and market demand, to play the guiding role of the government, scientific planning culture industry personnel training in china. Take the government led, market led "industry, University, research and production" combination of training mode, strengthen high-level professional and technical personnel innovation team training. According to the needs of cultural enterprises, the formation of specific cultural and creative talent team, encourage innovative thinking of large formation combat, to activate the creative spark and the formation of A single spark can start a prairie fire. The government can create the potential for a team to provide policy support, financial support and tax incentives, the construction of business service platform, strengthen business incubator, stimulate the creativity of cultural and creative team; actively organizing international and professional cultural and creative design contest, to carry out innovative achievements exhibition and trade, and promote the virtuous cycle and sustainable cultural creative team the development of.

2) We should develop the cultural and creative talents in an all-round way, increase the training and support of key personnel, key fields, special talents, highly skilled personnel and internationalized talents, and bring up a batch of leading personnel. Perfect government incentives, employers reward and social reward complementary multi-level cultural and creative design talent incentive system, for all kinds of creative design talent and creative activities, study and international exchange of incentives and funding. Strengthen propaganda, guide the great value of correct understanding of cultural creativity of the whole society in terms of value, create a conducive to cultivate high-end creative talents in social and cultural environment, the traditional culture is profound, can be together, at all times and in all countries make an original contribution to the cultural and creative talent shows itself master.

3) Give full play to enterprises and universities and research institutions in training the main role in the cultural and creative talents, support and encourage talent training base to establish related industries and industrial parks, leading enterprises and universities and research institutions. Cultural and creative industries are multidisciplinary and cross related. They combine culture, art, economy, management, science and technology and so on. They are both comprehensive and professional. The market is not lack of understanding of culture, skilled personnel, nor lack of understanding of planning, operation and management of talent, it is difficult to find these aspects of both complex talents. We should combine the market demand to speed up the optimization of professional settings, update the concept of innovative education, expand interdisciplinary knowledge and ability to integrate resources; based on strengthening the practice, focus on improving the ability of creative culture, science and technology innovation and marketing through the integration of the three.

4) Deepening the reform, breaking the system barriers, eliminating the barriers of identity, and creating a favorable environment for innovative talents to grow healthily and show their talents. The cultural and creative industries talent has the following characteristics: imagination and creativity, receptive to creative work; not willing to accept the shackles of restrictions and fetters tend to loose, free and fair competition in the working environment; work with greater mobility. Therefore, we can not judge the working style, value and contribution of cultural and creative talents according to the general rules, but should pay attention to their particularity, pursue long-term strategic value and long-term economic benefits. We should improve the use, flow, evaluation and incentive system in line with the characteristics of cultural and creative talents. We should adopt incentive management, flexible assessment and long-term evaluation of cultural and creative talents. 


\section{ACKNOWLEDGMENT}

2017 Xi'an Peihua University subject "The Belt and Road" strategy in Shaanxi under the background of cross-cultural training innovation and practice of "PHKT17025".

\section{REFERENCE}

[1] Wen jun. System thinking innovation of University "The Belt and Road" international talents training path [J]. International Business Journal of University of International Business and Economics, 2015 issue fifth

[2] Cheng ming. On the cultivation of cross cultural ability of Shaanxi College Students under the "Silk Road economy" [J]. Modern communication, August 2016

[3] Shang Wei CAI."Belt and Road Initiative" on the cultural industry challenges and suggestions on the development of cultural industry China [J]. Journal of Southwest University for Nationalities (HUMANITIES AND SOCIAL SCIENCES), 2016 issue fourth

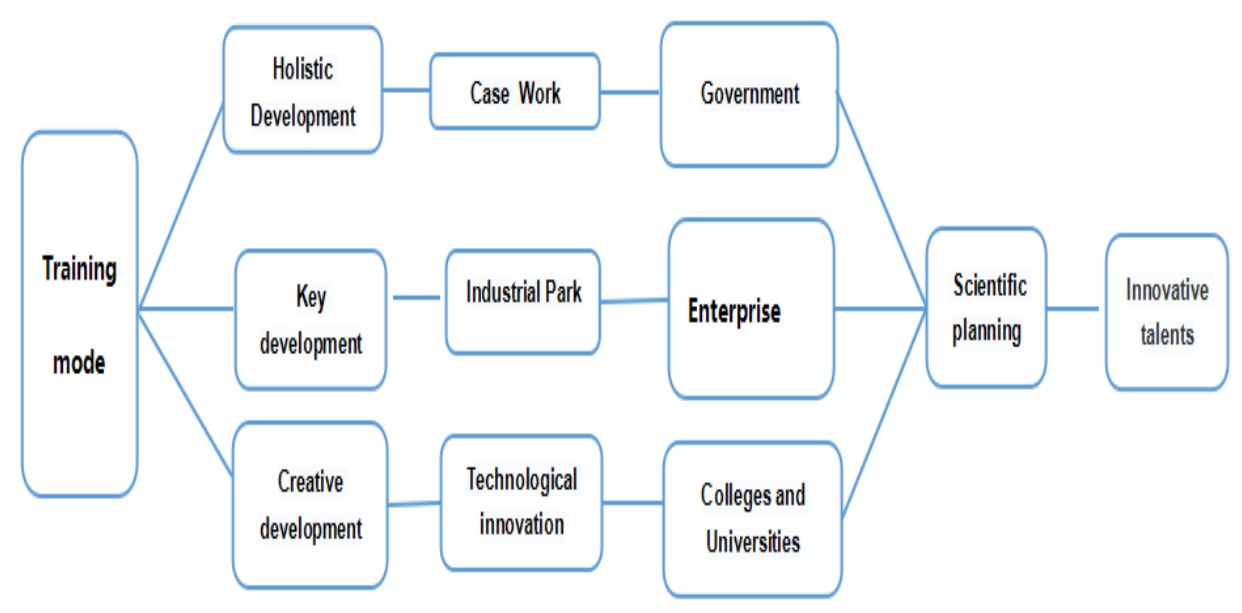

Figure 1. Chart 1Innovative talents training mode 